\title{
TEATRO CONTEMPORÁNEO: ALFONSO VALLEJO
}

\section{Francisco Gutiérrez Carbajo}

(Madrid: Universidad Nacional de Educación a Distancia, 2001, 213 páginas)

Alfonso Vallejo (Santander, 1943) es, además de dramaturgo, poeta y pintor, lo que le convierte en un creador polifacético, pero cuya inspiración pretende alcanzar un único objetivo: la representación del ser humano contemporáneo. Como dramaturgo, a pesar de que sus obras han sido representadas en países como Estados Unidos, Argentina, México, Venezuela, Inglaterra, Alemania, Italia y Polonia, y publicadas o premiadas con prestigiosos galardones en su mayor parte, aún no cuenta con el reconocimiento de los estudios críticos que le anclen dentro de la historia contemporánea de nuestro teatro. Por ello, el libro que Francisco Gutiérrez Carbajo acaba de publicar, es pionero en los estudios globales sobre la obra dramática de Alfonso Vallejo, ya que, hasta el momento, sólo podíamos encontrar algunos artículos diseminados en volúmenes más generales o de referencia.

Teatro contemporáneo. Alfonso Vallejo está compuesto de siete capítulos que abarcan desde la ubicación del dramaturgo hasta las refe- 
rencias bibliográficas. En el primero de ellos, titulado «El lugar del dramaturgo» (9-31), Francisco Gutiérrez Carbajo plantea la ardua tarea de enclavar la obra de Alfonso Vallejo en el panorama del teatro español de las últimas décadas. La mayoría de los críticos que se han referido a él (Fernández Santos, César Oliva, José Monleón, Enrique Llovet, María-José Ragué-Arias, entre otros) le clasifican dentro de los autores independientes de vanguardia, cuya principal peculiaridad es su postmodernidad underground, lo que le acerca al teatro de protesta y paradoja de otros dramaturgos españoles como Antonio Martínez Ballesteros, José Ruibal, Luis Riaza, Juan Antonio Castro, José María Bellido, Jerónimo López Mozo, Miguel Romero Esteo, Manuel Martínez Mediero, Luis Matilla, Ángel García Pintado. Todos ellos se fraguan en la sombra ideológica de Antonio Buero Vallejo, Alfonso Sastre y Lauro Olmo, y que podríamos perfectamente encuadrar en la geografía teatral de los O'Neill, Williams, Miller o Albee. Según Francisco Gutiérrez Carbajo, Alfonso Vallejo, «en todas sus obras, alcanza la universalidad, indagando en lo más profundo y misterioso del hombre como ser individual e irrepetible» (18). Es, además, un dramaturgo que escribe para actores y, por tanto, su teatro es acción, conflicto, tensión, osadía, ritmo, risa y rabia. El profesor Gutiérrez Carbajo hace un repaso minucioso de todas estas claves teatrales en la obra del dramaturgo.

En el segundo capítulo, «Itinerario por los temas de la dramaturgia de Alfonso Vallejo» (33-137), el más completo de este volumen, se nos ofrece una crítica extensa de cada una de las obras escritas por el autor. Se hace, primeramente, referencia a obras de su prehistoria teatral, que abarca desde 1966 a 1973. En 1966 estrena Cycle y en 1973 hace lo propio con Fly By. En ésta última el autor pretende evadirse de la realidad histórica del momento haciendo uso de la metáfora del vuelo. Es con Ácido sulfúrico - accésit del Premio Lope de Vega de 1975-con la que el dramaturgo inicia una trayectoria de gran reconocimiento crítico al plantear problemas de dependencia y de libertad, de autoridad y de poder, justo en el momento en que el régimen franquista veía su fin. A tumba abierta - premio Tirso de Molina en 1978 - entabla nuevamente la lucha contra el poder sin arma alguna, con su propia vida. En ella la muerte aparece unida a la guerra, presentada como un proceso desintegrador. No es menor el dramatismo de Monólogo para seis voces sin sonido, una obra que se desarrolla en el interior de una mente escindida, desintegrada, en la que al autor le interesa especialmente el funcionamiento del cerebro y analiza no sólo sus aspectos físiológicos, sino también todo lo psíquico y mental que lo completa y constituye. En El cero 
transparente - premio Fastenrath de la Real Academia en 1980- la frontera con lo mítico nos la proporciona el tránsito de una bajada a los infiernos, considerada ésta no como desvarío teológico, sino como imagen inesperable de la interioridad de cada hombre. Con El desguace - premio Lope de Vega de 1976- Alfonso Vallejo profundiza en el proceso de desintegración de la humanidad iniciado en obras anteriores, pero ya no se trata únicamente de la desintegración del hombre individual en una sociedad hostil a su desarrollo personal; se trata también del resquebrajamiento moral y físico de la sociedad. A estas obras le seguirán otras: Infratonos, Eclipse, Cangrejos de pared, Latidos donde la realidad se deforma para introducir en ella el pesimismo, el misterio, la muerte. En Monkeys y Gaviotas subterráneas se esfuerza por presentarnos una realidad humana en la que el hombre es un espejismo de la naturaleza. Estos temas vuelven a ser objeto de profundas reflexiones en sus últimas obras Sol ulcerado, Espacio interior, Week-End, La espalda del círculo y Höderlin, Orquídeas y panteras, Toby-después, Crujidos, Tuatú, Kora, Jindama, Ébola-Nerón, todas ellas diferentes en sus tramas, pero en el fondo late el mismo conflicto dialéctico entre el individuo y la sociedad, entre lo urbano y lo natural, entre la vida y la muerte, el poder y la libertad, que son, en definitiva, los grandes tema de las obras artísticas.

En el capítulo tercero, «Los personajes en busca de sí mismos» (139157), se fundamenta teóricamente la importancia capital de los personajes teatrales, recorriendo la obra de autores clásicos como Aristóteles y Cicerón y de otros contemporáneos como Harold Bloom, Fernando Feito Romo, Mijail Bajtín o Kurt Spang, para concluir que el procedimiento más notable en la representación de personajes es el de convertirlos en «emisores de información caracterizadora» (148), entre los que destacan la voz del propio autor y la de sus personajes o figuras. Pero frente a la singularización detallada de algunos caracteres hay otros que aparecen desprovistos de cualquier rasgo identificador. Los personajes del teatro vallejiano no se comportan siempre conforme a los rasgos indicadores de las caracterizaciones iniciales. Con frecuencia asistimos a una desinformación inicial estratégica, mediante la cual, existe un contraste entre lo que el autor dice de un personaje y lo que el personaje dice de sí mismo, o entre lo que el personaje dice de sí mismo y lo que de él opinan los demás.

En el capítulo cuarto, «La palabra y la contra-palabra» (159-185), se centra en el estudio del lenguaje teatral utilizado en las obras de Alfonso Vallejo, rebatiendo los supuestos teóricos de Bajtín, para quien el teatro, cuya marca formal es el diálogo, no sería un género dialógico, sino un 
género monologado. En el caso de Alfonso Vallejo, incluso la conciencia, aparece como un vasto theatrum mundi poblada de una multiplicidad de sujetos hablantes y de tiempos narrativos. Además, en sus obras nos encontramos variedad de códigos y registros que van desde el contacto intersubjetivo, pasando por el alarde de ingenio y la confesión, hasta un tipo de expresión que deja de ser interacción verbal para convertirse en diálogo de sordos. El lenguaje estándar, deviene en otras muchas obras, un instrumento insuficiente para transmitir los pensamientos y los sentimientos. Los propios personajes reconocen que han de recurrir a la contrapalabra o al silencio para establecer un adecuado vehículo comunicativo. Aparecen también en algunos de su dramas los extranjerismos, los tecnicismos propios de la medicina y de la psiquiatría, el préstamo o la cita literaria, y, en general, el recurso de la intertextualidad.

En el capítulo quinto, «Espacio geométrico y espacio fragmentado» (187-195), y en el sexto «Tiempo versus no-tiempo» (197-203) se analizan las consideraciones sobre el espacio y el tiempo de las obras de Alfonso Vallejo. Partiendo nuevamente de una base teórica (Gerard Genette, Iuri Lotman o Breyer) se argumenta que el espacio escénico de este dramaturgo está basado en lo neutro, lo estilizado, lo singularizado o lo concreto. Se pasa de obras con escenarios vacíos (Monkeys, El cero transparente, Toby-después) a otros espacios en conflicto como los hospitales, las cárceles y los manicomios (Fly-By, Monólogo para seis voces sin sonido). En todos los casos, el espacio escénico no es sólo el lugar donde se desarrolla la acción, sino que constituye una de las bases organizadoras en la construcción de una imagen del mundo. Otros de los tópicos estudiados y analizados desde la Antigüedad es el tiempo de la historia, el tiempo del discurso y el tiempo de la representación, el tiempo objetivo y el subjetivo. En las obras de Alfonso Vallejo encontramos ejemplos de todas estas modalidades que se ponen de manifiesto principalmente en las acotaciones o didascalias. En muchos casos, su obra no consiste en expresar el tiempo, sino más bien en abolirlo, en usar el no tiempo, las situaciones universales.

Teatro contemporáneo: Alfonso Vallejo nos parece un libro pionero que, sin duda, se convertirá en una obra de referencia obligada para los estudiosos, no sólo de la dramaturgia de Alfonso Vallejo, sino también del teatro español contemporáneo.

Dolores Romero López SELITEN@T/UNED 